\title{
ON THE RELATIONSHIP BETWEEN INTUITION, CONSCIOUSNESS AND COGNITION: IN SEARCH OF A UNIFIED CONCEPT OF MIND
}

\author{
Czesław S. Nosal \\ SWPS University of Social Sciences and Humanities \\ Faculty of Psychology, Campus in Wroclaw
}

This paper argues that within contemporary neuroscience and cognitive psychology a new theoretical framework is emerging for the integrated consideration of unconscious (intuitive) processing with conscious ones. This framework requires inclusion of new theories of the brain and consciousness dynamics (Baars, Damasio, Dehaene, Friston, Gazzaniga, LeDoux), evolution of the human memory system (Tulving), and theories of procedural, associative and working memory (Baddley, Reber). Evolutionarily old intuitive processing is not unique, and it is an integral component of any cognitive processes. A revolutionary new synthesis combining intuitive and conscious processing may take the form of a mind vector integrating the two.

Keywords: cognition; consciousness; intuition; intuitive processing; procedural memory.

CzesŁaw S. Nosal, https://orcid.org/0000-0002-1693-2692. Correspondence concerning this article can be addressed to CzesŁaW S. Nosal, SWPS Uniwersytet Humanistycznospołeczny, ul. Aleksandra Ostrowskiego 30b, 53-238 Wrocław, Poland; email: cnosal@swps.edu.pl.

Handling editors: Magdalena Szubielska \& Pawę StróżaK, John Paul II Catholic University of Lublin.

Received 17 April 2021. Received in revised form 13 Sept. 2021. Accepted 17 Sept. 2021. Published online 13 Oct. 2021. 
There is probably no cognitive process

that suffers from such a gap between phenomenological reality and scientific understanding. Introspectively, intuition is one of the most compelling and obvious cognitive processes; empirically and theoretically, it is one of the processes least understood by contemporary cognitive scientists (Reber, 1989, p. 232)

\section{ANCIENT QUESTIONS OF INTUITION. INTRODUCTION}

What is the relationship between intuition and the mechanisms of the current functioning of the mind? Are intuition and these mechanisms related to analytic processing? Are they two independent systems or are they closely related? In this paper I attempt to answer these questions. This is not an easy goal, because neither in cognitive psychology nor in cognitive neuroscience is there yet any systematized psychological knowledge about the mechanisms of intuition. The leading question is whether the separation of intuition and discursive cognition is still justified? I intend to argue that intuition and analytic cognition form an integrated functional system. However, in an evolutionary sense, intuitive processing is prior to analytical rationality.

The questions about the relation between intuition and cognition have a much longer history, dating back to antiquity. Great ancient thinkers noticed that human mind is not a homogenous system. They distinguished between primary cognition as "looking" inside the mind and discursive cognition, based on logical reasoning and concepts. The duality of the mind was unanimously recognized by such thinkers of Antiquity as Plato, Aristotle, and Plotinus. Popper (1992) states that the division made by the Plotinus between intuition and discursive thinking has become commonplace. However, the Latin term intuitio was not introduced until the 13th century by William of Moerbeke in order to accurately convey in translation the meaning of the Greek term epibolé, denoting a primary, comprehensive vision of an object, as opposed to the partial results of discursive cognition (Krapiec, 2003). There is no doubt that from ancient times to the present day the role of intuition has been recognized but not explained. 


\section{THE EVOLUTIONARY ROOTS OF INTUITION: BERGSON AND DESCARTES}

In the history of philosophy, much attention has been paid to intuition (Wadowski, 2013; Walczak, 2012). In the context of the main purpose of this article, I will only briefly contrast the positions of two great philosophers, Bergson and Descartes, because their views are very relevant to the main line of argument about the relationship between intuition and cognition. Of course, we are considering these positions from a different temporal perspective, which is why Bergson (the intuitionist) is ahead of Descartes (the rationalist) in this article.

For Bergson (1913), intuition was primary and separate from analytic reason, while for Descartes (2019), intuition was an essential heuristic that supported the direction of reasoning, and thus was the mental underpinning of rationality. According to Bergson, the instinct of intuition is closely related to the primal instinct of life, being in fundamental opposition to the structures of conceptual, linguistic, and conscious rational thought. Bergson sees, as Plotinus once did, a fundamental contradiction between the instinct of intuition and rationality, between the primitiveness of intuition and conscious reasoning. This means that intuition is based on different mechanisms than analytical rationality. The phrase "instinct of intuition" within Bergson's conception denotes a primitive, pre-rational "mind" that interacts with the drive of life (élan vital). And when rational reason emerges later in the course of evolution, the instinct of intuition, earlier on, unquestionably provides the basis for later rationality. Bergson thus argued that there is a fundamental dissonance between intuition and reason. The content of the subconscious messages of intuition is difficult to translate into the concepts and logic of rationality. This untranslatability of the implicit messages hidden in intuition is particularly evident in the field of creativity, broadly defined. Bergson's views express a kind of epistemological pessimism, emphasizing the untranslatability of the content of intuition into analytical and discursive messages. Thus, for Bergson, intuition and the rational mind are two independent systems. The fundamental contradiction between these systems of mind is that intuition is dominated by global, configurational processing, whereas analytic rationality is dominated by sequential, linear processing.

Descartes' (2019) position on intuition falls at the opposite pole from Bergson's views. The Descartes position can be characterized by a kind of epistemological optimism. He believed that only by relying on intuition could one successfully move toward clarity and simplicity, dividing complex mental structures into smaller and smaller cognitive units. In this process, intellectual intuition (intuitius mentis) was of fundamental importance, based on the analytical preparation of the object 
of cognition, so that later, thanks to intuition, one could move towards obvious and certain conclusions.

As a matter of fact, Descartes considered all processes fundamental for the course of logical reasoning, i.e. deduction, induction, enumeration and detection of analogies, to be closely related to acts of intuition (Janeczek, 2003; Wadowski, 2013; Walczak, 2012). Such an important role of intuition in Descartes' conception that influences the course of cognition is not surprising if we take into account that Descartes characterized the course of cognition as a certain heuristic process. Descartes devoted a separate work to organizing the rules of governing the mind (Descartes, 2002), within which intuition is the main rule that organizes cognition. Without doubt, then, Descartes is credited with discovering the important heuristic function of intuition.

\section{INSIGHT, INTUITION, COGNITIVE MAPS: KÖHLER AND TOLMAN}

In psychology, we owe the first concepts of intuition and insight mechanisms to researchers in gestalt psychology. Köhler analyzed insight mechanisms within this new paradigm, which revolutionized all psychology (Köhler, 1947). In Köhler's conception, insight was the act of mentally understanding the gestalt structure emerging in the course of solving a problem (1947). The final gestalt emerges as the result of an accumulation of irregular partial insights. This occurs in a process of dynamic "becoming" of new global structures from the partial structures that precede them. Köhler emphasized (1940) that this process has a variable organization, involving the interaction of several levels of processing. The concept of interaction is used by Köhler expressis verbis, emphasizing its importance in the general description of the functioning of the mind. However, interaction processes are selective. Thanks to them, only certain patterns (gestalts) are singled out and others are omitted.

For Köhler, interaction is the main process determining the variable extraction of cognitive patterns. Köhler (1940) gives the concept of interaction a realistic sense. $\mathrm{He}$ emphasizes that it corresponds to the process of emergence of the gestalt as a cognitive pattern. Interaction takes place in a mental field that connects elements and relations. In this field, various relations are previously and unconsciously "tried out" before a specific gestalt, through an act of insight, emerges in consciousness as the final solution.

Köhler's concept comes from a different era, but it is still important in the description of unconscious cognitive transformations occurring in networks. This is 
because Köhler emphasized that the processes of dynamic change in the figure-background relation concern the course of all cognitive processes, especially perception and thinking. Thus, the processes of emergence of structures are universal. Only some of them appear at the level of consciousness as acts of sudden insights.

Köhler (1959) even makes a kind of demythologization of the role of insight in the thinking process. He criticizes the phrase "solution by insight" and shows that insight is only the final result of processing occurring in subconscious processes. Insight is thus a kind of "message" to consciousness, which it "informs" that an initial solution has been found at the subconscious level. Within Köhler's conception, intuition corresponds to unconscious emergence processes, the final result of which is insight.

Gestalt psychologists did not use intuition as a theoretical term, but their well-founded arguments concerning the role of emergence and the different routes of insight testify that they took into account the influence of processes occurring beyond conscious control. Only Duncker (1935) uses the term intuition, referring to the intuitive criterion of obviousness and Husserl's (1900) "imperative of intuition".

According to Köhler and Dunker, insight is not a random process because it is determined by complex interactions taking place in the mental field. Köhler's concept contained only an outline of the dynamics of the interaction of unconscious and conscious processing. It was further developed by Tolman (1949), who presented a theory of the mechanism of changes in the mental field and the mental operations occurring in it. Tolman precisely describes a kind of working mental field containing cognitive means-end-field representations (Tolman's terminology). The structure of these representations changes in the process of reaching the final solution. As Tolman writes, this structure exhibits "creative instability", expressed by a constant exploration of the environment. This process occurs within a cognitive map, an induced semantic network whose elements are in a relationship of mutual substitutability, roundaboutness and mutual opposition (Tolman's terminology). Through the play of these relations the network is constantly changing, the final solution appears. Undoubtedly, Tolman pioneered a new conception of the mechanisms of insight attainment that can be operationalized today by measuring individual differences in cognitive styles.

Tolman's conception points to the important role of implicit mechanisms linking conscious and unconscious processing. Tolman also points to the regulatory role of perceived "mental distances" between means-end-field elements. Interestingly, contemporary research on intuition also uses judgements of sensing the "closeness" of a solution. Tolman recognized the role of these judgements much earlier as unconscious preferences. In later studies, the sense of "closeness to a solution" was shown 
to be preceded by an increase in emotional arousal, as measured by skin-galvanic response indices (Damasio, 1999; Tikhomirov, 1976).

\section{SYNERGY, INTUITION AND RATIOMORPHISM: DAMASIO AND BRUNSWIK}

Did a neuronal organization of the mind take shape in course of biological evolution determining the interaction of evolutionarily prior mechanisms of intuition with later rational processing? From the perspective of contemporary knowledge, it can be argued that there has been a partial reconciliation of these extremes in the process of evolution. As Jajnes (1976) beautifully writes, there was a breakdown of the bicameral brain, a new neuronal organization emerged, a hierarchical consciousness. Perhaps this breakdown, fortunately, is not complete and through intuition the "old mind" speaks to us?

Within the new organization, the role of intuition is still important as it is the basis of cognition. This is definitely stated by Damasio (2011) that a synergy of unconscious with conscious processing has taken shape within the structures of the mind, involving cognitive maps and image representations. Earlier Damasio (1994) characterizing intuition pointed out that its function is the unconscious selection of variants of possible decisions and results of creative thinking.

Equally definitely, Koch (2004) emphasizes the importance of intuitive unconscious processing. Thus, it can be argued that intuitive processing is not something marginal, but is in constant readiness and vigilance in relation to ongoing conscious processing, constituting its inalienable background.

Acknowledging the duality of intuition in relation to discursive cognition, one must, however, seek to answer the question about the relationship between these two forms of mind functioning. Duality does not imply a disconnection between intuition and discursive cognition. Two main lines of analysis of the relation between intuition and cognition come into play. The first is the long line of evolution of the mind, that is, the formation of various forms of mental regulation concurrent with the process of differentiation and development of life forms.

This line of development and transformation of the cognitive capacities of the mind is closely related to the genesis of consciousness. The mind does not exist without consciousness, within which the integration of old brain structures with new ones takes place. From contemporary theories of the evolution of consciousness, it follows that consciousness is a kind of hyperstate, a complex neuronal stream that integrates the courses of many neurobiological and mental processes (Damasio, 
2011; Dehaene, 2014; Gazzaniga, 2019; Koch, 2004; LeDoux, 2019; Reber 2019). Thus, both old intuitive mechanisms and rational, analytical processing mechanisms continually interact within this neuronal hyperstate. The evolutionary process of consciousness presented by Gazzaniga (2019) begins with an ontological leap, closely related to the emergence of life and the experience of subjective sensations. LeDoux (2019), developing this important theme in close reference to Tulving's theory (1985, 1987), presents how the emergence of noetic memory representing self-awareness is of great importance in this process. Thanks to this, intuition obtains the status of an "observer" in the human mind.

In our analysis of the evolution of the mind, we ask about the long line of changes that led to the emergence of the human mind through the transformation of the various forms of less complex minds that preceded it. What was at the beginning of this long sequence of changes? What original form of cognition was involved in life? A plausible answer to these questions is precisely the emergence of intuition as a function of the organism's global apprehension of the situation with the simultaneous orientation of adaptation processes to the variability/uncertainty of the environment. However, this does not mean that the form of intuition is the same in all living organisms. Its initial forms are different in simple organisms and different in organisms equipped with a central nervous system. But, this ontological leap that Gazzaniga (2019) writes about has resulted in even very simple organisms having some initial form of intuition. Intuition in simple and complex organisms shares one common function in the form of the ability to grasp situations globally.

When analyzing the evolution of cognition, Lorenz (1978) gives a very puzzling example that even an amoeba has the ability to make a "global assessment", although it has no nervous system. And the global apprehension of a situation or insight is the main function of intuition, in line with the ancient Greek sense of the term epibole quoted above. Even very simple animal minds, for example the minds of octopuses, whose "brains" are subordinated to a distributed processing organization, have the capacity to learn and orient themselves effectively to their environment (Godfrey-Smith, 2018). And Reber (2019) pushes this boundary to even earlier evolutionary stages and much simpler organisms.

The psychology of mind has been relatively late in recognizing the importance of implicit, unconscious, intuitive primary processes that form the functional basis for the whole mind. These primary processes are described by Lorenz (1978) as $r a-$ tiomorphic. They are processes analogous to logical one, but they are not the same as the regulation of cognition by rules of analytical reason. Thus, even such relatively simple organisms as amoebas adapt effectively to their environment through implicit intuitive, ratiomorphic mechanisms. These combine globality and directionality into a new whole. 
The concept of ratiomorphic tendency was introduced by Brunswik (1954), a pioneer in ecological psychology, when characterizing the primary mechanisms of perception (Nosal, 2017). Brunswik claimed that this concept extends an idea introduced much earlier by von Helmholtz (1977). He pointed out that visual perception mechanisms are based on intuitive "unconscious inference" and on "intuition of space". The speed of perception was explained by von Helmholtz by the influence of intuition. It followed that perceptual processes are based on mechanisms functioning implicitly, thanks to which in the brain there is a rapid integration of many processes determining the recognition of perceptual patterns.

\section{INTUITION IN THE STREAM OF CONSCIOUSNESS: GAZZANIGA AND JUNG}

The above-presented analysis of the evolution of intuition and its basic functions in the mind leads to the conclusion that intuition determines a certain constantly operating, underlying system of unconscious and automatic processing. The functions of this system include the global representation of the state of the situation and, as a further consequence, the ratiomorphic direction of the adaptation process. This process operates on generalized cognitive vigilance and unconscious selection of decision (action) options. The globalization of the apprehension of the situation and the related cognitive vigilance is expressed by the state of diffuse scanning of the field of attention and the search for information in the environment. At the elementary behavioral level, this corresponds to orientation reflexes, exploration of the environment and cognitive curiosity (Sokolov, 1963). At the highest level of human personality structure, it corresponds to open-mindedness, correlated with intuition and fantasy (McCrae \& Costa, 2003). This correlation indicates that open-mindedness does not only refer to orientation to the environment, but also includes a second direction, openness to "old mind" messages, i.e. intuition.

The globality of situation apprehension and exploration of the environment determine different patterns of interaction of the old intuitive (unconscious) processing with the new conscious processing. Both types of structures, remain in a synergistic path of relationship (Damasio, 2011). These interactions are thus inherent components of brain functioning in any cognitive processes. Both types of constant relationship create a functional whole in the mind, within which, however, the "figure-background" relationships change. The figure is formed by relatively narrow, changing conscious processing, but the figure does not exist without its unconscious, stabilizing, much more extensive background. The dialectic of constant 
change of figure and background is fundamental to the functioning of the mind. It is interesting to note that it is this dialectic that is modelled in mathematical theories of the brain functioning; I will present these later.

Using the phrase "instinct of consciousness", Gazzaniga (2018) emphasizes the biological primitiveness of consciousness as an inalienable function of living beings. This view is in the spirit of Bergson's conception, although Gazzaniga does not use the term "intuition". He considers globality, subjectivity and integrating as the main functions of consciousness, and thus uses terms that we already know from the features of intuition. Thanks to the function of integrating, neuronal representations flowing from individual, "lower" brain modules, form new wholes at the highest level. According to Gazzaniga's theory, these neuronal streams flowing "from below", only at the higher levels of the brain are integrated, sequentially ordered, creating a global grasp of the world's variability and the relative stability of subjective experience as a feature of consciousness. Although at the highest level of brain work the main features of consciousness (globality, subjectivity) are still stabilized, at the lower levels, consciousness is a pulsating, changing process. Thus, it is an essentially heterogeneous process, within which various lower-level states/ processes may alternately dominate.

The description of consciousness as a heterogeneous process, alternately performing different functions, brings together classical stream-of-consciousness theories and recent neuroscientific theories synthesized by Baars (1988), Dehaene (2014). Gazzaniga (2018), LeDoux (2019) and Reber (2019). Among the classical concepts, the theory of the basic functions of consciousness presented by Jung (1997) holds a special place. He was the first psychologist to place intuition expressis verbis in the set of basic functions of consciousness, alongside functions such as perception, feeling, and thinking. From the theory presented by Jung (1997) in his Psychological Types, he characterized intuition as a primary, innate function of consciousness, referring to Bergson's concept.

Researchers of intuition and implicit learning agree that Jung pioneered the psychology of intuition (Reber, 1989; Westcot, 1968). Jung's theory also contains a certain evolutionist message. Indeed, the basic four functions described by Jung form two pairs with different evolutionary distance. Intuition and perception are irrational functions because they are evolutionarily prior and operate outside subject-determined rationality. Feeling and thinking, on the other hand, are, according to Jung, rational functions in the sense that they involve mechanisms of making judgements that are relativized to the knowing/feeling subject.

Intuition and perception, as two evolutionarily earlier functions of consciousness, are thus peculiar anchors of the mind, combining orientation in the environment with a simultaneous global assessment and experiencing of the situation. In turn, 
rational functions express subjective evaluations (emotions, feelings) and criteria of logical consistency (thinking). In his description of intuition, Jung (1935) drew attention to its very important compensatory function, stating that intuition "patches up holes" (Jung's metaphor) occurring in perception, emotions and thinking. Jung's theory was developed in an era of scant knowledge about the brain. However, Jung's intuitive insight into the heterogeneity of consciousness is astonishing. I believe that Gazzaniga's contemporary neurobiological theory of consciousness has a distant precursor in Jung. The circle of history closes, the instinct of life (Bergson) and the instinct of consciousness (Gazzaniga) obtain a new theoretical framework in the evolutionary theory of the basic functions of consciousness (Jung).

\section{THE NEUROCOGNITIVE BASIS AND COMPENSATORY FUNCTION OF INTUITION IN CURRENT INFORMATION PROCESSING: BAARS, TULVING, REBER, FRISTON}

The view that intuition is an inherent component of information processing in the human mind provides only some general description. It must, indeed, be supplemented with answers to more specific questions: 1 . What constitutes the neurocognitive basis of primary, unconscious intuitive processing? 2. How does the mechanism of intuitive processing interact continuously with ongoing conscious processing? Attempting to answer these questions requires a much broader view of the functioning of the mind.

Evolutionally, the mind emerged as a four-sided limited system. Thanks to this, current information processing, carried out in working memory, is relatively isolated from other systems and effectively adapted to environmental variability (Nosal, 2010). Therefore, the theory of working memory mechanisms is important in the analysis presented in this article. This is because it includes mechanisms concerning the strong connections of variable "current" processing with processes of attention displacement, regulation changes, and with access to knowledge resources in longterm memory (LTM) (Baddley, 2012). In a metaphorical sense, working memory encompasses an active "little mind" functioning within a complex neuronal network and under constraints.

Four constraints protect current processing from information overload. However, they are not total constraints, but partial and variable as a function of time. In detail, current processing in working memory is relatively isolated from four sides: 1) from the fluctuations of the attentional field and short-term memory; 2) from the access to the resources of declarative knowledge and experience contained in LTM 
networks; 3) from the intrusions of associations contained in the subconscious and unconscious; 4) from the programs regulating cognitive control, understanding, reflection, that is, from the programs of metacognition.

All of the above-mentioned limitations are partial, because in the course of the mind's functioning they are compensated by various detailed mechanisms, about which a lot of fragmentary knowledge has already been accumulated in cognitive psychology. However, the main direction of cognitive compensation is related to the influence of unconscious intuitive processing, which forms the background for the central figure of mind functioning.

In ongoing functioning, the central role is played by working memory operating in a complex network of variable, heterogeneous consciousness that alternates between different functions. So, in a fuller description of the interaction of intuition with ongoing cognition, theories of the dynamic organization of consciousness (Baars, 1988; Dehaene, 2014; Gazzaniga, 2018; LeDoux, 2019) and the theory of the evolution of the memory system (Tulving, 1985, 1987) need to be taken into account.

An important key aspect of this description is the "alternation of function" during processing, as there is a continuous exchange of its information content within the limited scope of working memory. Due to the alternation of functions, the active "figure" of working memory can be dynamically combined with various detailed mechanisms of the mind. Presumably, the alternation of functions has its expression in the spectral organization of brain activity, through which sequential and configurational processing can be integrated (Nosal, 2009). As an aside, it is worth noting briefly that in the pioneering classical syntheses of brain functioning, integrative processes were considered crucial (Luria, 1973; Pribram, 1971).

Baars' (1988) theory characterizes a global working space of consciousness within which narrow working memory mechanisms operate. A later development of Baars' theory by Dehaene (2014) clearly indicates that there is a constant interaction of conscious and unconscious (intuitive) processing in the brain. For a fuller account of this interaction, it is necessary to refer to the evolutionary theory of memory system structure (Tulving, 1985, 1987). This theory has also become central in describing the evolution of consciousness (LeDoux, 2019). In this article it will be used in presenting the fundamental role of intuition.

Tulving describes the human memory system as monohierarchical because it is a whole within which three systems function. They are separate but functionally strongly related. The basis of this monostructure is procedural memory, on which, in turn, semantic and episodic (noetic, autobiographical) memory is based. Strictly speaking, procedural memory is the basis of all processes occurring in the brain. It is the basic form of memory, determining implicit learning as the basis of intuition (Reber, 1989). The essence of this form of learning is the spontaneously operating 
associative networks in the brain. So, to the question of what constitutes the neurocognitive basis of intuition we have an answer in the form of active procedural associative networks.

These networks are in constant readiness to form associations, but this readiness is probably inherently divergent. This is the essence of the evolutionary "invention" of intuition. Therefore, association formation is subject to the rule of redundant information fixation. This is confirmed by Reber's (1967) early research on the unconscious assimilation/detection of symbol sequences. The associative network of the brain somewhat resembles an amoeba. It is characterized by a diffuse cognitive orientation in the process of forming implicit structures that determine intuitive patterns.

However, the role of procedural memory and associative networks is much broader than was initially thought after its discovery by Brenda Milner in 1957. The role of procedural memory is fully explained by the framework of Tulving's theory (1985). In essence, any processing relies on procedural memory, but not only. It is also thought that this type of memory underpins the development and changes occurring in temperament and personality structure, changes determined by implicit associative learning (Cloninger et al.,1993). Given this, it seems promising to look for the importance of intuition on a broader scale, and not only in relation to cognition. This possibility has partial support in the pioneering study of the relationship between personality and intuition (Westcott, 1968).

The important role of intuition in consciousness and cognition also has an interesting confirmation in general, mathematical models of the brain functioning (Friston, 2010; Friston et al., 2020). These models describe the dynamics of changes in the network connecting the subconscious to consciousness. These models, involving complex neuronal streams, are represented formally by stochastic processes in the form of Markovian chains. Within them an operational, more detailed, Bayesian mechanism play the central role. This is referred to as the hierarchical active inference model (Friston, 2010; Friston et al., 2020) based on intuitive a priori distributions, which are then transformed into distributions of specific a posteriori judgments/predictions. Consciousness researchers emphasize (LeDoux, 2019) that the central principle of brain functioning is predictive inference, the principle of anticipation, and that the brain is an "organ" acting on a non-existent future. And anticipation is the assumption (a priori, implicite) that there is a state of affairs that de facto does not yet exist. Sechenov in 1878 was the first to point out that anticipation is a central principle of the brain (Berlyne, 1963; Sechenov, 1965). However, this general Bayesian model of the brain immersed in Markov chains must be combined with the principle of spectral organization mentioned earlier. Formally speaking, this principle corresponds to Fourier transforms. 
In all of the formal models mentioned here, if we interpret them realistically, the role of intuitive processing is important. This is because both the changes in transformations of a priori/a posteriori distributions and their temporal cycles (Fourier dynamics) are based on patterns implicit in neuronal networks of the brain. They represent the globality of processing and at the same time anticipation as the main function of intuition in the brain. However, this function of intuition has a dual focus, linking the globally represented past with the analogous possibilities of the future; what has happened with what is yet to come. This is a rather risky statement but one might think that the three types of formal models mentioned (Bayes, Fourier, Markov), while characterizing different aspects of brain functioning, also include the influence of intuition.

\section{CONCLUSION: \\ FUNCTIONS OF INTUITION IN CONSCIOUSNESS AND COGNITION}

From the considerations presented in this article, a more general conclusion emerges that intuitive processing permeates the entire functioning of the mind, forming its basis. It is processing inherent in the organization of consciousness and the evolution of the human memory system. Intuition works constantly, finding itself dormant because it is older than analytical, conscious rationality. However, the influence of intuition is most clearly seen in creative thinking, aesthetic pattern recognition, and processes of linguistic understanding and performance. The constant vigilance of intuition is particularly evident in linguistic performance. It influences the formulation of statements in advance and thanks to it linguistic errors are corrected. Presumably, the style of linguistic utterances depends on the level of intuition (Piegzik, 2021). Chomsky (2016) emphasizes that complex linguistic expressions appear in the mind at a glance and interact closely with those that are inaccessible. Many years ago Freud pointed out the same thing: we do not consciously choose our words but simply speak (Kandel, 2018). Freud's and Chomsky's statements can be seen as support for the mentioned above Damasio's thesis on the synergy of old with new mechanisms of mind functioning.

Without intuition there is no art, language, thinking, and creativity. From time immemorial, prominent creators have remarked that their consciousness was surprised by new ideas, regardless of the creative field. These high registers of creativity have long provided spectacular evidence of the influence of intuition.

Intuition can be defined as stable and widespread implicit processing occurring in the brain on the basis of procedural memory mechanisms. This processing occurs 
continuously and in two directions, from bottom up and from top down. The first direction is expressed by the dominance of the influence of uncontrolled, spontaneous emergence of structures contained in LTM. Emerging cognitive units can be simple bisociations or complex cognitive relations and patterns. The second direction of emergence of intuitive results involves the partial influence of conscious control, as occurs in problem solving and acts of cognitive insight.

The primary function of intuition can be noticed primarily in the organization of processing in the stream of consciousness. The central "figure" in it is occupied by the mechanisms of working memory, but they cannot be effective without a functional "background", i.e. the global working space. Thanks to the constant readiness of this space and the updating of various implicit influences in it, working memory remains in functional, spectrally variable connections with the flow of control, variability of attention, access to LTM. Implicit resources are updated multidirectionally in the course of solving cognitive tasks, e.g., in the course of speaking/writing activities, and are updated involuntarily, spontaneously, through unexpected intrusions of association. The role of implicit processes based on procedural memory requires a new look at implicit learning quite differently. They occur automatically and presumably do not require reinforcement, as do classical (Pavlovian) and instrumental (Skinnerian) learning processes.

An instructive analogy to illustrate the constant relationship between intuition and cognition is the strong connection of central and peripheral vision. We keep track of changes in the environment through one relatively narrow convergent central vision, but the two fields of peripheral vision are on constant alert, spontaneously joining in the centripetal process when discrepancies or some surprising intrusions suddenly appear in the background. So we have one quite rational, convergent central "eye" and two intuitive, divergent peripheral eyes. No wonder that in ancient Greece intuition was considered the inner eye of the mind. The cited analogy can be extended to the relationship between intuition and cognition. The only problem is whether conscious central processing is sensitive to the subconscious messages of intuition. In terms of this sensitivity, Jung believed, there are individual differences. This is particularly evident in the context of creative thinking, when excessive control blocks new associations coming from the subconscious.

The primitiveness of intuition, however, also has its disadvantages, because it can be the cause of too fast, wrong judgments and decisions. In such situations reason should compensate for the deficiencies of intuition. Unfortunately, quite often it is the other way round, intuition "patches up holes" and compensates for the weaknesses of reason, although the scientific knowledge about intuition is developing slowly. It is very likely that we are on the eve of a new revolutionary synthesis combining intuitive and conscious processing. 


\section{REFERENCES}

Baars, B. J. (1988). A cognitive theory of consciousness. Cambridge University Press.

Baddley, A. (2012). Working memory: Theories, models, and controversies. Annual Review of Psychology, 63, 1-29. https://doi.org/10.1146/annurev-psych-120710-100422

Bergson, H. (1913). Introduction to metaphysics. Liberal Arts Press.

Berlyne, D. E. (1963). Structure and direction in thinking. John Wiley.

Brunswik, E. (1955). "Ratiomorphic" models of perception and thinking. Acta Psychologica, 11, 108-109. https://doi.org/10.1016/S0001-6918(55)80069-8

Chomsky, N. (2016). What kind of creatures are we? Columbia University Press.

Cloninger, C. R., Svrakic, D. M., \& Przybeck, T. R. (1993). A psychobiological model of temperament and character. Archives of General Psychiatry, 50(12), 975-990. https://doi.org/10.1001/archpsyc.1993.01820240059008

Damasio, A. (1994). Decartes' error: Emotion, reason, and the human brain. Penguin Books.

Damasio, A. (1999). The feeling of what happens: Body and emotion in the making of consciousness. Harcourt College Publishers.

Damasio, A. (2011). Self comes to brain: Constructing the conscious brain. Vintage Books.

Dehaene, S. (2014). Consciousness and the brain: Deciphering how the brain codes our thoughts. Viking.

Descartes, R. (2019). Rozprawa o metodzie [Discourse on the method] (T. Żeleński, Trans.). Wydawnictwo Vis-á-vis Etiuda.

Descartes, R. (2002). Reguly kierowania umystem. Poszukiwanie prawdy poprzez światto umystu [Rules for the direction of the mind. Seeking truth by the light of the mind]. Wydawnictwo Antyk.

Friston, K. (2010). The free-energy principle: A unified brain theory? Nature Reviews Neuroscience, 11, 127-138. https://doi.org/10.1038/nrn2787

Friston, K. J., Wiese, W., \& Hobson, J. A. (2020). Sentience and the origins of consciousness: From Cartesian duality to Markovian monism. Entropy, 22(5), 516. https://doi.org/10.3390/e22050516

Gazzaniga, M. (2019). The consciousness instinct. Farrar Straus \& Giroux.

Godfrey-Smith, P. (2018). Other minds: The octopus, the sea and the deep origins of consciousness. Farrar Straus \& Giroux.

Helmholtz, H. von (1977). Epistemological writings. Reidel Publishing Company.

Husserl, E. (1900). Logische Untersuchungen. Niemeyer.

Jajnes, J. (1976). The origin of consciousness in the breakdown of the bicameral mind. Mariner Books. Janeczek, S. (2003). Logika czy epistemologia [Logics or epistemology]. Wydawnictwo KUL.

Jung, C. G. (1997). Typy psychologiczne [Psychological types] (R. Reszke, Trans.). Wydawnictwo Wrota.

Jung, C. G. (1935). Uber Grundlagen der analytischen Psychologie. Walter Verlag.

Kandel, E. (2018). Disordered mind: What unusual brains tell us about ourselves. Macmillan Publishers.

Koch, C. (2004). The quest for consciousness: A neurobiological approach. Roberts \& Company Publishers.

Krąpiec, M. (2003). Intuicja [Intuition]. In Powszechna Encyklopedia Filozofii (pp. 897-901). Wydawnictwo KUL.

Köhler, W. (1940). Dynamics in psychology. Liveright Publication Company.

Köhler, W. (1947). Gestalt psychology. Liveright Publication Company.

LeDoux, J. (2019). The deep history of ourselves. The four-billion-year story of how we got. Penguin Books. 
Lorenz, K. (1978). Behind the mirror: A search for a natural history of human knowledge. Mariner Books.

Luria, A. R. (1973). The working brain. An introduction to neuropsychology. Penguin Books.

McCrae, R. R., \& Costa, P. T. (2003). Personality in adulthood: A five factor theory perspective. The Guilford Press.

Nosal, C. S. (2010). Umysł czterostronnie ograniczony: Bariery i kompensacje w poznawaniu [The fourfold-limited mind: Barriers and compensations in cognition]. Poznańskie Studia z Filozofii Humanistyki, 4, 5-25.

Nosal, C. S. (2011). Interakcja inteligencji i intuicji: Nowa teoria funkcjonowania umysłu [The interaction between intelligence and intuition: New theory of mind functioning]. Czasopismo Psychologiczne, 17, 207-218.

Nosal, C. S. (2016). Klasyczne teorie wglądu i ich znaczenie dla współczesnej wiedzy o mechanizmach intuicji: Integracja koncepcji Köhlera i Tolmana [The classic theories of insight and their importance for contemporary knowledge of intuition: Integration of Köhler's \& Tolman's concepts]. In T. Rzepa \& C. W. Domański (Eds.), Na Drogach i Bezdrożach Historii Psychologii (Vol. 6, pp. 35-50). Wydawnictwo UMCS.

Nosal, C. S. (2017). Racjomorfizm i pierwotność intuicji w teorii Egona Brunswika [Ratiomorphism and primary nature of intuition in Egon Brunswik's theory]. In T. Rzepa \& C. W. Domański (Eds.), Na Drogach i Bezdrożach Historii Psychologii (Vol. 6, pp. 49-62). Wydawnictwo UMCS.

Piegzik, W. (2021). Od intuicji językowej do zachowań intuicyjnych w języku. Wydawnictwo Naukowe PWN.

Popper, K. (1972). Objective knowledge: An evolutionary approach. Clarendon Press.

Pribram, K. (1971). Languages of the brain. Prentice Hall.

Reber, A. (1967). Implicit learning and artificial grammars. Journal of Verbal Learning and Verbal Behavior, 6(6), 855-863. https://doi.org/10.1016/s0022-5371(67)80149-x

Reber, A. (1989). Implicit learning and tacit knowledge. Oxford University Press.

Reber, A. (2018). The first minds: Caterpillars, karyotes, and consciousness. Oxford University Press.

Sechenov, I. M. (1965). Reflexes of the brain: An attempt to establish the physiological basis for psychological processes. The MIT Press.

Sokolov, E. N. (1963). Perception and the conditioned reflex. Pergamon Press.

Tichomirow, O. K. (1976). Struktura czynności myślenia człowieka [The structure of human thinking activity]. Państwowe Wydawnictwo Naukowe.

Tolman, E. C. (1949). Purposive behavior in animals and man. University of California Press.

Tulving, E. (1985). How many memory systems are there? American Psychologist, 40(4), 385-398. https://doi.org/10.1037/0003-066x.40.4.385

Tulving, E. (1987). Multiple memory systems and consciousness. Human Neurobiology, 6(2), 67-80.

Wadowski, J. (2013). Rewindykacja intuicji. Wybrane aspekty filozoficznej i teologicznej interpretacji zagadnienia [Reclaiming intuition. Selected aspects of philosophical and theological interpretation]. Ateneum.

Walczak, M. (2012). Wglad i poznanie. Epistemologia Bernarda J. F. Lonergana [Insight and cognition. Bernard Lonergan's epistemology]. Wydawnictwo KUL.

Westcott, M. (1968). Toward a contemporary psychology of intuition. Holt Company. 